\title{
THE ROLE OF FAULT QUOTIENT IN DETERMINATION OF THE DISTANCE TO A TRANSMISSION LINE FAULT
}

\author{
J. Survilo \\ Riga Technical University, \\ 1 Kronvalda Blvd. 1, Riga, LV-1010, LATVIA
}

\begin{abstract}
The notion of fault quotient refers to single-phase-earth and phase-to-phase faults in one-terminal and two-terminal (double fed), single or parallel power lines at determination of the distance to a fault place using the apparent impedance method. The fault quotient is determined as the ratio of the current through a fault place (fault current) to the current in a faulty phase at single-phase-earth faults and to the difference of currents in faulty phases at phase-to-phase faults. For one-terminal lines at single-phase-earth faults, neglecting capacitive and load currents, this ratio is 1 , and for phase-to-phase faults it equals $1 / 2$. For other cases it is a complex quantity, with the absolute value $>1$ for single-phase-earth faults. Its significance grows with the fault resistance $R_{f}$. At $R_{f}=0$ this ratio loses its significance for determination of the distance to a fault place. The tangent of the fault quotient angle with a real axis enters into the ultimate expressions for the reactance to fault place and for the fault resistance. The use of such a quotient facilitates reiterative calculations of the distance to a fault place.

Key words: distance protection, fault resistance, single-phase-earth fault, phase-to-phase fault.
\end{abstract}

\section{INTRODUCTION}

To determine the distance from a monitoring point to the fault place of a damaged high voltage power line, the specified voltages and currents are to be known. In a damaged one-terminal power line (the line fed from the monitored side only) such voltages and currents of the monitored end of the line alone are sufficient for this purpose. At the same time, in a faulty two-terminal line (fed from both sides) or a line with a parallel one, the current through a fault place is the sum of that from the monitored end and of those from the remote end of the line or/and from the parallel line. This causes difficulties at determination of the distance to the fault place if the fault resistance is non-zero and the currents of the far end of the line are not known. However, without sophisticated measures based on the communication of the remote end currents only the currents of monitored end are available. This difficulty can be overcome and the fault current of the remote end of a double fed power line can be calculated if the impedances of the system to which the remote power line end is connected are known: zero-sequence impedance for a single-phase earth fault [1], and positive sequence impedance for a phase-to-phase fault [2]. When the remote end fault currents are known, the current through a fault place can be determined and, consequently, the fault quotient can be found. This quotient plays the key role at determination of the positive sequence reactance from 
the monitoring point to a fault place. For radial medium-voltage grids without dead grounding of the neutral the fault quotient takes into account the zero-sequence capacitive currents and the currents of compensation devices.

\section{SINGLE PHASE-EARTH FAULT IN A SINGLE TWO-TERMINAL LINE}

To consider a single phase-earth fault in parallel lines, the main points of such a fault in a solitary line [1] (arranged in the most appropriate order of handling) must be reminded. In this case we have a classical expression for apparent impedance $\dot{Z}_{a}$ to a fault place consisting of its real $\left(R_{a}\right)$ and imaginary $\left(X_{a}\right)$ parts (see, for example, in [3]):

$$
\dot{Z}_{a}=\frac{\dot{U}_{p h}}{\dot{I}_{p h}+\dot{K}_{N} \dot{I}_{g}} ; R_{a}=\operatorname{Re}\left(\dot{Z}_{a}\right) ; X_{a}=\operatorname{Im}\left(\dot{Z}_{a}\right)
$$

where $\dot{U}_{p h}$ is the faulty phase voltage;

$\dot{I}_{p h} \quad$ is the faulty phase current;

$\dot{I}_{g}$ is the ground current,

$\dot{K}_{N}$ is a compensation coefficient:

$$
\dot{K}_{N}=\frac{1}{3} \frac{\dot{Z}_{0 s p}-\dot{Z}_{1 s p}}{\dot{Z}_{1 s p}}
$$

with $\dot{Z}_{0 s p}$ and $\dot{Z}_{1 s p}$ being the specific (per kilometer) zero-sequence and positive sequence impedances to fault place, respectively, which are supposed to be known for the power line under consideration. Further on, the quantities denoted by subscripts " $s p$ " will represent specific values. The impedances of expression (2) are:

$$
\dot{Z}_{1 s p}=R_{c s p}+j X_{1 s p} ; \quad \dot{Z}_{0 s p}=R_{0 s p}+3 R_{g s p}+j X_{0 s p},
$$

where $R_{c s p}$ is the active resistance of phase conductor;

$R_{0 s p}$ is the zero-sequence active resistance of phase conductor;

$R_{g s p}$ is the ground resistance;

$X_{1 s p}$ and $X_{0 s p}$ are the direct and zero-sequence reactances.

In Fig. 1, the circuit diagram of a faulty line is reproduced from [1].

At the beginning, we should introduce two basic quotients and two auxiliary coefficients as follows.

The current quotient:

$\dot{k}=\frac{\dot{I}_{g}}{\dot{I}_{p h}}=\frac{3 \dot{I}_{0 l}}{\dot{I}_{p h}}=k^{\prime}+j k^{\prime \prime} ; \quad k^{\prime}=\operatorname{Re}(\dot{k}) ; \quad k^{\prime \prime}=\operatorname{Im}(\dot{k})$,

where $\dot{I}_{g}$ and $\dot{I}_{0 l}$ are the ground current and zero-sequence current, respectively, at the monitoring point,

$\dot{I}_{g}=3 \dot{I}_{0 l}$ 
and the fault quotient:

$$
\dot{k}_{f}=\frac{\dot{I}_{f}}{\dot{I}_{p h}}=k_{f}^{\prime}+j k_{f}^{\prime \prime} ; \quad k_{f}^{\prime}=\operatorname{Re}\left(\dot{k}_{f}\right) ; \quad k_{f}^{\prime \prime}=\operatorname{Im}\left(\dot{k}_{f}\right)
$$

where $\dot{I}_{f}$ is the fault current (the current through a fault place), which at a singlephase earth fault consists of tripled zero-sequence currents from both sides of the line:

$$
\dot{I}_{f}=3\left(\dot{I}_{0 l}+\dot{I}_{0 r}\right) \text {. }
$$

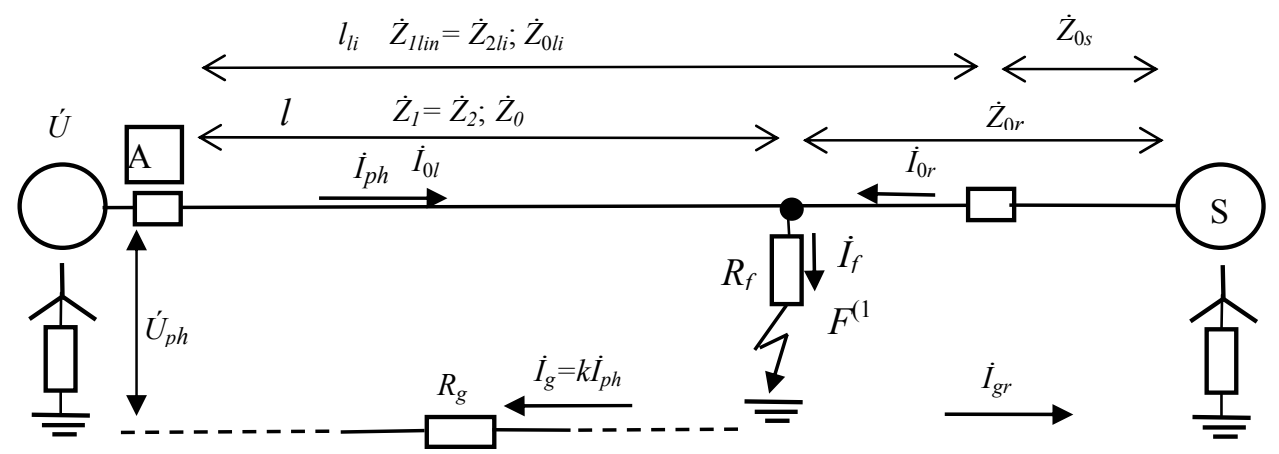

Fig. 1. Circuit diagram of a line faulty phase:

A - protection device; $\dot{U}_{p h}$ - phase voltages at installation point; $R_{f}$ - fault resistance (between faulty phase wire and earth); $F^{(1)}$ - single-phase earth fault; $\mathrm{S}$ - electric system on the line's far end; $l_{l i}$ and $l$-power line's length and distance to fault place $(\mathrm{km}) ; \dot{Z}$ - corresponding impedances.

Two auxiliary coefficients are based on specific power line parameters:

1) the resistance coefficient

$$
\dot{k}_{d R}=\frac{R_{c s p}+\dot{k}_{g p s p}}{R_{s s p}}=k_{d R^{\prime}}+j k_{d R}{ }^{\prime \prime},
$$

where $k_{d R}{ }^{\prime}=\operatorname{Re}\left(\dot{k}_{d R}\right) ; \quad k_{d R}{ }^{\prime \prime}=\operatorname{Im}\left(\dot{k}_{d R}\right)$.

$R_{c s p}$ is from (3),

$R_{g p s p}$ is the putative ground resistance and

$R_{\Sigma s p}$ is the simple summary resistance:

$$
R_{g p s p}=\frac{R_{0 s p}-R_{c s p}}{3}+R_{g s p} ; \quad R_{\Sigma s p}=R_{c s p}+R_{g p s p},
$$

where $R_{0 s p}$ and $R_{g s p}$ are taken from (3);

2) the reactance coefficient

$$
\dot{k}_{d X}=\frac{(3-\dot{k}) X_{1 s p}+\dot{k} X_{0 s p}}{3 X_{\Sigma s p}}=k_{d X}{ }^{\prime}+j k_{d X}{ }^{\prime \prime} ;
$$


where

$$
k_{d X}{ }^{\prime}=\operatorname{Re}\left(\dot{k}_{d X}\right) ; \quad k_{d X}{ }^{\prime}=\operatorname{Im}\left(\dot{k}_{d X}\right),
$$

with $X_{1 s p}$ and $X_{0 s p}$ taken from (3) and $X_{\Sigma s p}$ being simple summary reactance:

$$
X_{\Sigma s p}=\frac{1}{3}\left(2 X_{1 s p}+X_{0 s p}\right) .
$$

Based on real $R_{a}$ and imaginary $X_{a}$ parts of $Z_{a}$ given by the microprocessor device, we have a system of two equations with two unknowns: $X_{1}$ is the reactance to fault place and $R_{f}$ is the fault resistance. To solve this system for $X_{1}$ and $R_{f}$, the following proportions between the reactance and other line parameters are employed:

$$
a=\frac{R_{c s p}}{X_{1 s p}} ; \quad b=\frac{R_{\Sigma s p}}{X_{1 s p}}=\frac{R_{c s p}+R_{g p s p}}{X_{1 s p}} ; \quad c=\frac{X_{\Sigma s p}}{X_{1 s p}}=\frac{2 X_{1 s p}+X_{0 s p}}{3 X_{1 s p}} .
$$

To simplify the expressions for reactance to fault place $X_{1}$ and fault resistance $R_{f}$, the following three extra designations should be introduced:

$$
\begin{aligned}
& f^{\prime}=a b k_{d R}{ }^{\prime}-a c k_{d X}{ }^{\prime \prime}+b k_{d R}{ }^{\prime \prime}+c k_{d X}{ }^{\prime} ; \quad f^{\prime \prime}=a b k_{d R}{ }^{\prime \prime}+a c k_{d X}{ }^{\prime}-b k_{d R}{ }^{\prime}+c k_{d X}{ }^{\prime \prime} ; \\
& h=\left(k_{d R}{ }^{\prime 2}+k_{d R}{ }^{\prime \prime 2}\right) b^{2}+2\left(k_{d R}{ }^{\prime \prime} k_{d X}{ }^{\prime}-k_{d R}{ }^{\prime} k_{d X}{ }^{\prime \prime}\right) b c+\left(k_{d X}{ }^{\prime 2}+k_{d X}{ }^{\prime \prime 2}\right) c^{2} .
\end{aligned}
$$

The intermediate quantities $d^{\prime}$ and $d^{\prime \prime}$ for checking the correctness of the preceding calculations are:

$$
d^{\prime}=\frac{R_{c s p}+k^{\prime} R_{g p s p}}{X_{1 s p}} ; \quad d^{\prime \prime}=\frac{k^{\prime \prime} R_{g p s p}}{X_{1 s p}} .
$$

Coefficients $A$ and $C$ are to be equal to $a$ and 1, respectively [4]:

$$
\begin{aligned}
& A=\frac{d^{\prime} f^{\prime}+d^{\prime \prime} f^{\prime \prime}+c\left(k_{d X} f^{\prime \prime}-k_{d X}{ }^{\prime \prime} f^{\prime}\right)}{h}=a ; \\
& C=\frac{c\left(k_{d X} f^{\prime}+k_{d X}{ }^{\prime \prime} f^{\prime \prime}\right)+d^{\prime \prime} f^{\prime}-d^{\prime} f^{\prime \prime}}{h}=1 .
\end{aligned}
$$

Now, the sought-for quantities are:

$$
\begin{aligned}
& X_{1}=\frac{B X_{a}-D R_{a}}{B-a D}=\frac{\left(f^{\prime}+f^{\prime \prime} \operatorname{tg} \varphi_{f}\right) X_{a}-\left(f^{\prime} \operatorname{tg} \varphi_{f}-f^{\prime \prime}\right) R_{a}}{f^{\prime}\left(1-\operatorname{atg} \varphi_{f}\right)+f^{\prime \prime}\left(\operatorname{tg} \varphi_{f}+a\right)} ; \\
& R_{f}=\frac{R_{a}-a X_{a}}{B-a D}=\frac{h\left(R_{a}-a X_{a}\right)}{k_{f^{\prime}}\left[f^{\prime}\left(1-\operatorname{atg} \varphi_{f}\right)+f^{\prime \prime}\left(\operatorname{tg} \varphi_{f}+a\right)\right]}
\end{aligned}
$$

Coefficients $B$ and $D$ are taken from [4] (not shown separately). 
The sought-for distance to a fault place is:

$$
l=\frac{X_{1}}{X_{1 s p}} .
$$

The role of fault quotient $\dot{k}_{f}$ is hidden in the $\operatorname{tg} \varphi_{f}$ of (16) and (17):

$$
\operatorname{tg} \varphi_{f}=\frac{k_{f}^{\prime \prime}}{k_{f}^{\prime}} .
$$

In a one-terminal line the fault quotient is 1 (neglecting the fault current), because there is no current from the far end. To find $\dot{k}_{f}$ in a single two-terminal line the fault current flowing from both sides should be known; however, to know it, the value of the distance to fault place is needed. The fallacious circle can be torn by iterative calculations [1].

The same method based on the fault quotient can be applied to single-phaseearth faults in the medium-voltage grids without dead-earthed neutral [1]. In the mentioned work, the expression for the fault quotient is more general, since the fault current - together with other quantities - contains zero-sequence capacitive currents.

\section{SINGLE PHASE-EARTH FAULT \\ IN PARALLEL TWO-TERMINAL LINES}

In parallel two-terminal lines the fault current consists of three components: the current of a faulty line, the current from the system at the line's opposite side, and the current from a parallel line.

The wiring diagram of a parallel double-circuit two-terminal line is depicted in Fig. 2. Only zero-sequence quantities are shown, since, as is known, positive and negative sequence couplings do not exist in transposed power lines [5].

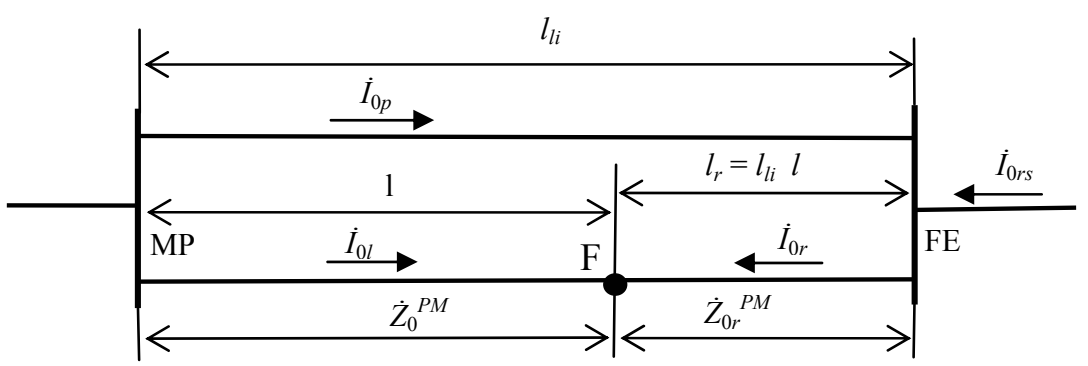

Fig. 2. Circuit diagram for zero-sequence currents of single-phase earth fault in a double twoterminal line: $\dot{Z}_{0}{ }^{P M}$ - impedance of the faulty line from monitoring point MP to fault place $\mathrm{F}$ taking into account zero-sequence mutual inductance $X_{0}{ }^{m}$ between two parallel lines; $\dot{Z}_{0 r}{ }^{P M}$ - impedance of the faulty line from far end FE to fault place F taking into account $X_{0}{ }^{m}$; zero-sequence currents: $\dot{I}_{0 l}-$ current from the monitoring point to the fault place; $\dot{I}_{0 p}$-current of the parallel line; $\dot{I}_{0 r}$-current to the fault place from the line's right side, $\dot{I}_{0 r s}$ - current from a far system; $l_{l i} ; l ; l_{r}$ - the lengths of the power line and its segments. 
The zero-sequence impedance of a faulty line to fault place $\dot{Z}_{0}{ }^{M}$, taking into account mutual reactance $X_{0}^{m}$ between two lines on the span from the monitoring point to the fault place, is:

$$
\dot{Z}_{0}{ }^{M}=\dot{Z}_{0}+j \dot{\kappa} X_{0}{ }^{m},
$$

where $\dot{Z}_{0}$ is the zero-sequence impedance to the fault place without mutual reactance (with two lines assumed to be infinitely far from one another);

$\dot{\kappa}$ is the parallel current quotient to the left of the fault place on Fig. 2, which can be calculated since currents $\dot{I}_{0 p}$ and $\dot{I}_{0 l}$ are supposed to be measured or calculated out of three-phase currents or of the ground current (not to be confused with current quotient $\dot{k}$, see (4)):

$$
\dot{\kappa}=\frac{\dot{I}_{0 p}}{\dot{I}_{0 l}} ;
$$

the mutual reactance, in turn, is:

$$
X_{0}{ }^{m}=\omega L^{m},
$$

where $L^{m}$ is the mutual zero-sequence inductance between the faulty and the parallel line from the monitoring point to the fault place.

To use ultimate formulas (16), (17) and (18), a great number of quantities should be calculated. First of all, zero-sequence specific parameters of a faulty line on the left side of the fault point must be considered based on the mutual inductance between the faulty and the parallel line and zero-sequence current $\dot{I}_{0 p}$ in the latter. To denote this, in the formulas below superscript $M$ appears. The specific value of the zero-sequence active resistance of the phase conductor is denoted $R_{0 s p}{ }^{P}$ to underscore that this quantity relates to the line parallel to another one (indicated by superscript $P$ ). The specific value (per $\mathrm{km}$ ) of the mutual reactance between two parallel lines is denoted $X_{0 s p}{ }^{m}$. The quantities based on these specific parameters should also be recalculated. Respective expressions are brought together in the following set of formulas:

$$
\begin{aligned}
& \dot{X}_{0 s p}{ }^{C}=X_{0 s p}+\dot{\kappa} X_{0 s p}{ }^{m} ; \quad X_{0 s p}{ }^{M}=\operatorname{Re}\left(\dot{X}_{0 s p}{ }^{C}\right) ; \quad R_{0 s p}{ }^{m}=\operatorname{Im}\left(\dot{X}_{0 s p}{ }^{C}\right) ; \\
& R_{0 s p}{ }^{P M}=R_{0 s p}{ }^{P}-R_{0 s p}{ }^{m} ; \quad R_{g p s p}{ }^{P M}=\frac{R_{0 s p}{ }^{P M}-R_{c s p}}{3}+R_{g s p} ; \\
& \dot{Z}_{0 s p}{ }^{P M}=R_{0 s p}{ }^{P M}+3 R_{g s p}+j X_{0 s p}{ }^{M} ; \quad \dot{K}_{N}{ }^{P M}=\frac{\dot{Z}_{0 s p}{ }^{P M}-\dot{Z}_{1 s p}}{3 \dot{Z}_{1 s p}} ; \\
& \dot{Z}_{a}=\frac{\dot{U}_{p h}}{\dot{I}_{p h}+\dot{K}_{N}{ }^{P M} \dot{I}_{g}}=\frac{\dot{U}_{p h} \dot{I}_{p h}+3 \dot{K}_{N}{ }^{P M}}{} ; \quad R_{\Sigma s p}{ }^{P M}=R_{c s p}+R_{g p s p}{ }^{P M} ;
\end{aligned}
$$




$$
\begin{aligned}
& X_{\Sigma s p}{ }^{M}=\frac{2 X_{1 s p}+X_{0 s p}{ }^{M}}{3} ; \quad b=\frac{R_{\Sigma s p} P M}{X_{1 s p}} ; \quad c=\frac{X_{\Sigma s p} P M}{X_{1 s p}} ; \\
& \dot{k}_{d R}=\frac{R_{c s p}+\dot{k}_{g p s p} P M}{R_{\Sigma s p} P M}=k_{d R^{\prime}}{ }^{\prime}+j k_{d R^{\prime \prime}} ; \\
& \dot{k}_{d X}=\frac{(3-\dot{k}) X_{1 s p}+\dot{k} X_{0 s p}{ }^{M}}{3 X_{\Sigma s p}{ }^{M}}=k_{d X^{\prime}}+j k_{d X}{ }^{\prime \prime} ; \quad d^{\prime}=\frac{R_{c s p}+k^{\prime} R_{g p s p} P M}{X_{1 s p}} ; \\
& d^{\prime \prime}=\frac{k^{\prime \prime} R_{g p s p} P M}{X_{1 s p}} .
\end{aligned}
$$

In the above expressions, new designations mean the following: $X_{0 s p}{ }^{C}$ is the complex zero-sequence specific reactance, which includes the real and imaginary parts of product $\dot{\kappa} X_{0 s p}{ }^{m} ; R_{0 s p}{ }^{m}$ is the imaginary part of $\dot{\kappa} X_{0 s p}{ }^{m}$, which reacts like a negative resistance as related to zero-sequence current $\dot{I}_{0 l}$; the quantities with superscript $P M$ take into account zero-sequence resistances $R_{0 s p}{ }^{P}$ and $R_{0 s p}{ }^{m}$ of the power line; and subscript $\Sigma s p$ denotes the summary specific quantity.

A further procedure (relating to the left side of the line) is conducted as in Sect. 2 with the following coefficients: $A=a, C=1$.

Second, the specific parameters of a faulty line to the right of the fault place should be considered with the aim to find fault quotient $\dot{k}_{f}$. Taking into account that the zero-sequence current on the right side of a faulty line flows in the opposite direction to the current in the parallel line, the impedance from the line's right end to the fault place (being denoted by subscript $r$ ) is:

$$
\dot{Z}_{0 r}{ }^{M}=\dot{Z}_{0 r}-j \dot{\kappa}_{r} X_{0 r}{ }^{m},
$$

where the right parallel current quotient $\dot{\kappa}_{r}$ is defined analogously to (21):

$$
\dot{\kappa}_{r}=\frac{\dot{I}_{0 p}}{\dot{I}_{0 r}} .
$$

Quotient $\dot{\kappa}_{r}$ defined by formula (25) can not be calculated because current $\dot{I}_{0 r}$ is just the sought-for value. Here we again run into the fallacious circle: to determine one quantity, the second one is to be known, and vice versa. To tear this circle, fault current $\dot{I}_{f}$ (Fig. 3) should be found using the specific value of zerosequence impedance $\dot{Z}_{0 s p r}{ }^{M}$ of the line's right side, which takes into account the mutual inductance, with the right side current quotient $\dot{\kappa}_{r}$ assumed to be known $\left(\dot{\kappa}_{\text {rass }}\right)$ : 


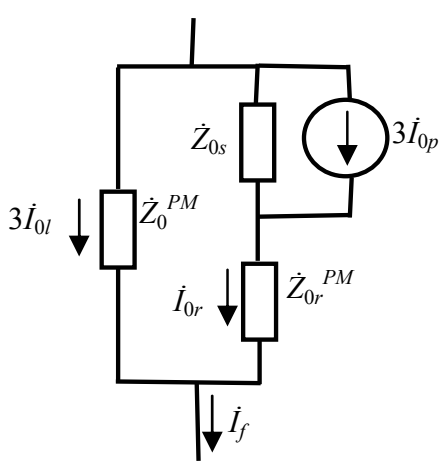

Fig. 3. Formation of fault current $\dot{I}_{f}$.

$$
\dot{Z}_{0 s p r}{ }^{P M}=\dot{Z}_{0 s p}{ }^{P}-j X_{0 s p} \dot{\kappa}_{\text {rass }},
$$

where zero-sequence specific impedance $\dot{Z}_{0 s p}{ }^{P}$ is:

$$
\dot{Z}_{0 s p}{ }^{P}=R_{0 s p}{ }^{P}+3 R_{g s p}+j X_{0 s p} .
$$

Zero-sequence reactances of the faulty line's left and right sides are:

$$
\dot{Z}_{0}{ }^{P M}=\dot{Z}_{0 s p}{ }^{P M} l_{\text {ass }} ; \quad \dot{Z}_{0 r}{ }^{P M}=\dot{Z}_{0 s p r}^{P M}\left(l_{l i}-l_{\text {ass }}\right) ;
$$

where $l_{l i}$ and $l_{\text {ass }}$ are the length of faulty line and the assumed distance to the fault place, respectively.

The fault current consists of three components (Fig. 3):

$$
\dot{I}_{f}=\dot{I}_{g}+\dot{I}_{0 r s}+\dot{I}_{0 r p},
$$

where $\dot{I}_{0 r s}$ and $\dot{I}_{0 r p}$ are the currents to the fault place from the line's far end system and from the parallel line, respectively:

$$
\dot{I}_{g}-(\operatorname{see}(5)) ; \quad \dot{I}_{0 r s}=\dot{I}_{g} \frac{\dot{Z}_{0}^{P M}}{\dot{Z}_{0 r}^{P M}+\dot{Z}_{0 s}} ; \quad \dot{I}_{0 r p}=3 \dot{I}_{0 p} \frac{\dot{Z}_{0 s}}{\dot{Z}_{0 r}{ }^{P M}+\dot{Z}_{0 s}} \text {. }
$$

The fault current determined, the quantities $X_{l} ; l ; R_{f}$ can be found by (16)(18). Based on the calculated distance $l$ to the fault place, the distance to fault place $l_{a s s}$ can be assumed, and current quotient $\dot{\kappa}_{r}$ can be calculated by (25) for the next cycle of iteration where $\dot{I}_{0 r}$ is:

$$
\dot{I}_{0 r}=\dot{I}_{0 r s}+\dot{I}_{0 r p} \text {. }
$$

To calculate the distance to the fault place using the iteration process, the following input data should be known: faulty line parameters $X_{1 s p}, X_{0 s p}, R_{c s p}, R_{0 s p} P$, $R_{g s p}, X_{0 s p}{ }^{m}$; zero-sequence impedance of the system $\dot{Z}_{0 s}$ to which the far end of the faulty line is connected; length of the faulty line $l_{l i}$; measured fault quantities: $\dot{U}_{p h}$, $\dot{I}_{p h}, \dot{I}_{0 l}$ or $\dot{I}_{g}, \dot{I}_{0 p}$. The following quantities must be calculated: $\dot{\kappa}$ by $(21) ; X_{0 s p}{ }^{C}$, 
$X_{0 s p}{ }^{M}, R_{0 s p}{ }^{m}, R_{0 s p}{ }^{P M}, R_{g p s p}{ }^{P M}$ by (23); $\dot{Z}_{1 s p}$ by (3); $\dot{Z}_{0 s p}{ }^{P M}, \dot{K}_{N}{ }^{P M} ; \dot{Z}_{a}$ by (23); $R_{a}, X_{a}$ by (1); $R_{\Sigma s p}{ }^{P M}, X_{\Sigma s p}{ }^{P M}$ by (23); $a$ by (12); b,c by (23); $\dot{k}, k^{\prime}, k^{\prime \prime}$ by (4); $\dot{k}_{d R}$ by

(23); $k_{d R}, k_{d R}$ " by (8); $\dot{k}_{d X}$ by (23); $k_{d X}, k_{d X}$ " by (10); $d^{\prime}, d^{\prime \prime}$ by (23); $h, f^{\prime}, f^{\prime \prime}$ by

(13) and $A, C$ by (15) using quantities by (23), $A=a, C=1 ; \dot{Z}_{0 s p}{ }^{P}$ by (27).

Now we can start the first iteration cycle consisting of the following steps:

1) assume the initial value of right side current quotient $\dot{\kappa}_{\text {rass }}{ }^{(0)}=0$;

2) assume the initial value of distance to fault place $l_{\text {ass }}{ }^{(0)}$, e.g. $l_{l i} / 2$;

3) $\dot{Z}_{0 s p r} P M(1)$ by (26);

4) $\dot{Z}_{0}^{P M(1)}, \dot{Z}_{0 r}^{P M(1)}$ by (28);

5) $\dot{I}_{0 r s}{ }^{(1)}, \dot{I}_{0 r p}{ }^{(1)}$ by (30);

6) $\dot{I}_{f}^{(1)}$ by (29);

7) $\dot{k}_{f}^{(1)}, k_{f}{ }^{(1)}, k_{f}^{\prime \prime(1)}$ by (6);

8) $\operatorname{tg} \varphi_{f}^{(1)}$ by (19);

9) $X_{I}^{(1)}, l^{(1)}$ and $R_{f}^{(1)}$ by (16), (18) and (17);

10) $\dot{I}_{0 r}{ }^{(1)}$ by (31);

11) $\dot{\kappa}_{r}^{(1)}$ by (25).

The second iteration cycle will be:

1) assume the first value of right side current quotient $\dot{\kappa}_{\text {rass }}{ }^{(1)}$ which can be taken equal to $\dot{\kappa}_{r}{ }^{(1)}$;

2) assume the initial value of distance to fault place $l_{\text {ass }}{ }^{(1)}$ which must be taken close to calculated $l^{(1)}$; continue the second iteration cycle similar to the first one.

Continue the process until the calculated value of distance to fault place $l$ is sufficiently close to its assumed value $l_{\text {ass }}$. If at the $n$-th cycle $l_{\text {ass }}^{(n-1)}$ is chosen successfully, then $l^{(n)}=l_{\text {ass }}^{(n-1)}$.

If necessary, the capacitive currents can also be taken into account - for instance, in the cable lines with small load currents. The consideration can be made on the basis of [1]. As the phase voltage of a faulty line the quantity $\dot{U}_{p h}{ }^{\prime}$ must be taken instead of $\dot{U}_{p h}$ :

$$
U_{p h}{ }^{\prime}=\dot{U}_{p h}-\Delta \dot{U}_{p h}
$$

where $\Delta \dot{U}_{p h}$ is the result of symmetrical $\Delta \dot{I}_{1 c f}$

and zero-sequence $\Delta \dot{I}_{0 c f}$ capacitive currents in the faulty line:

$$
\Delta \dot{U}_{p h}=\Delta \dot{I}_{1 c f} \dot{Z}_{1}+\Delta \dot{I}_{0 c f} \dot{Z}_{0}^{P M} .
$$

The fault current $\dot{I}_{f}$ grows by zero-sequence capacitive currents of the faulty line $\dot{I}_{0 c l i}$, of the remote system $\dot{I}_{0 c s}$ and of a parallel line $\dot{I}_{0 c p}$. 


\section{PHASE-TO-PHASE FAULT IN A TWO-TERMINAL LINE}

The problem has been treated in [2]. The location of a fault place was considered for phase-to-phase faults in a power line fed from both sides. The results of calculation were however not precise enough because the iteration process did not converge in a proper way. The influence of short-circuit current from the opposite side of the line was not taken into account to the necessary extent. This can be corrected using the notion of the current quotient. We shall proceed on the basis of the wiring diagram shown in Fig. 4 (reproduced from [2]). We will begin with the loop current equation set:

$$
\begin{aligned}
& \left(2 \dot{Z}+R_{f}\right) \dot{I}_{1}+R_{f} \dot{I}_{I I}-\dot{Z} \dot{I}_{I I I}=\dot{E}_{C B} ; \\
& R_{f} \dot{I}_{I}+\left[2\left(\dot{Z}_{e}-\dot{Z}\right)+R_{f}\right] \dot{I}_{I I}+\left(\dot{Z}_{e}-\dot{Z}\right) \dot{I}_{I I I}=\dot{e}_{C B} ; \\
& -\dot{Z} \dot{I}_{I}+\left(\dot{Z}_{e}-\dot{Z}\right) \dot{I}_{I I}+2 \dot{Z}_{e} \dot{I}_{I I I}=\dot{E}_{B A}-\dot{e}_{B A} .
\end{aligned}
$$

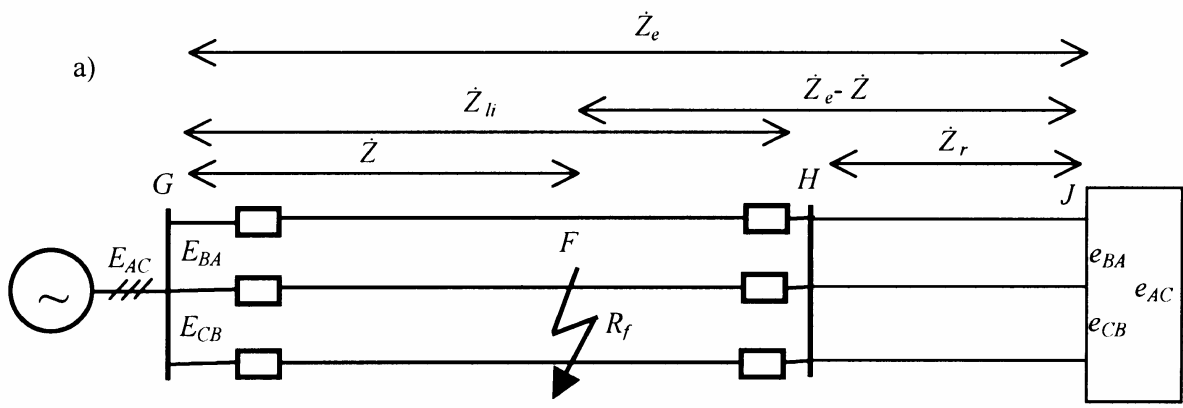

b)

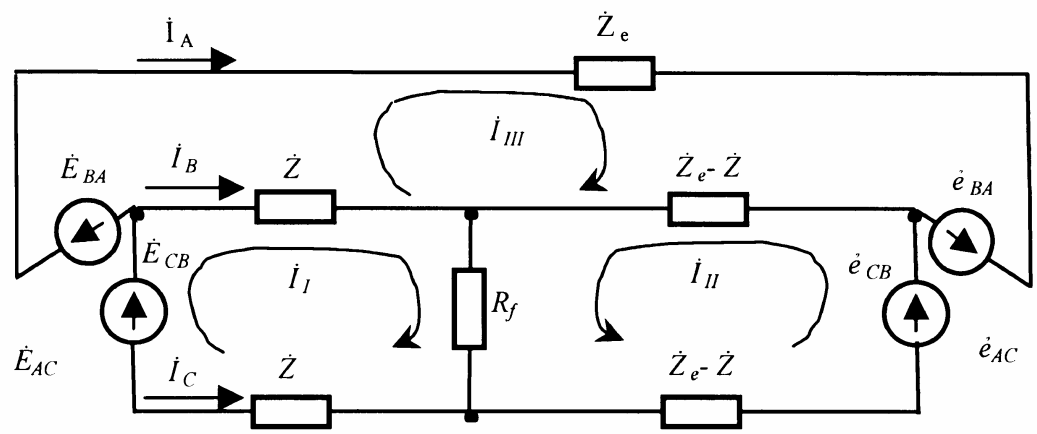

Fig. 4. Phase-to-phase short-circuit in a power line fed from both sides: $a$ ) wiring diagram of the grid; $b$ ) equivalent scheme of the grid.

$\dot{E}_{A C}, \dot{E}_{B A}, \dot{E}_{C B}$ - line voltages at monitoring point $\mathrm{G} ; \dot{e}_{A C}, \dot{e}_{B A}, \dot{e}_{C B}$ - equivalent voltages at remote grid point J; $\dot{Z}_{l i}$-positive sequence impedance of the faulty line; $\dot{Z}$ - positive sequence impedance of the line between monitoring $\mathrm{G}$ and fault $\mathrm{F}$ points; $\dot{Z}_{r}$ - positive sequence impedance of the remote system; $\dot{Z}_{e}$ - entire positive sequence impedance from point $\mathrm{G}$ to point $\mathrm{J} ; R_{f}$ - fault (arc) resistance; $\dot{I}_{A}, \dot{I}_{B}, \dot{I}_{C}$ - phase currents; $\dot{I}_{I}, \dot{I}_{I I}, \dot{I}_{I I I}-$ loop currents.

The entire positive sequence impedance from monitoring point $\mathrm{G}$ to remote system $\mathrm{J}$ is

$$
\dot{Z}_{e}=\dot{Z}_{l i}+\dot{Z}_{s} .
$$


At the monitoring point, the phase currents and line voltages can be measured, therefore loop currents $\dot{I}_{I}, \dot{I}_{I I}$ and their differences can be known:

$$
\dot{I}_{I}=-\dot{I}_{C} ; \quad \dot{I}_{I I I}=\dot{I}_{A} ; \quad \dot{I}_{I}-\dot{I}_{I I I}=\dot{I}_{B} .
$$

Observing (36), the first equation of set (34) can be rewritten as

$$
\begin{aligned}
& \dot{E}_{C B}=\dot{Z}\left(\dot{I}_{B}-\dot{I}_{C}\right)+R_{f}\left(\dot{I}_{I I}-\dot{I}_{C}\right)= \\
& \quad=\left(R_{c}+j X_{1}\right)\left(\dot{I}_{B}-\dot{I}_{C}\right)+R_{f}\left(\dot{I}_{I I}-\dot{I}_{C}\right),
\end{aligned}
$$

where $R_{c}$ is the active resistance of the phase conductor;

$X_{1}$ is the positive sequence reactance to the fault place.

If fault resistance $R_{f}$ is zero, the first equation of set (34) gives the wellknown expression for the impedance to fault place:

$$
\dot{Z}=\frac{\dot{E}_{C B}}{\dot{I}_{B}-\dot{I}_{C}}=R_{c}+j X_{1} .
$$

In reality, fault resistance $R_{f}$ is not equal to zero but has some positive value.

For that reason, proceeding further, we should rely on (37), which can be rewritten as

$$
\frac{\dot{E}_{C B}}{\dot{I}_{B}-\dot{I}_{C}}=R_{c}+j X_{1}+R_{f} \frac{\dot{I}_{I I}-\dot{I}_{C}}{\dot{I}_{B}-\dot{I}_{C}}
$$

Now, the expression $\dot{E}_{C B} /\left(\dot{I}_{B}-\dot{I}_{C}\right)$ gives a distorted value of the impedance to the fault place which will be called apparent impedance $\dot{Z}_{a}$ from the monitoring point to a phase-to-phase fault place, consisting of real $R_{a}$ and imaginary $X_{a}$ apparent parts:

$$
\dot{Z}_{a}=\frac{\dot{E}_{C B}}{\dot{I}_{B}-\dot{I}_{C}} ; \quad R_{a}=\operatorname{Re}\left(\dot{Z}_{a}\right) ; \quad X_{a}=\operatorname{Im}\left(\dot{Z}_{a}\right) .
$$

The ratio $\left(\dot{I}_{I \Gamma} \dot{I}_{C}\right) /\left(\dot{I}_{B}-\dot{I}_{C}\right)$ can be called phase-to-phase fault quotient $\dot{k}_{f f}$ consisting of its real $k_{f f}{ }^{\prime}$ and imaginary $k_{f f}{ }^{\prime \prime}$ parts:

$$
\dot{k}_{f f}=\frac{\dot{I}_{I I}-\dot{I}_{C}}{\dot{I}_{B}-\dot{I}_{C}} ; \quad k_{f f}{ }^{\prime}=\operatorname{Re}\left(\dot{k}_{f}\right) ; \quad k_{f f}{ }^{\prime \prime}=\operatorname{Im}\left(\dot{k}_{f}\right) .
$$

Now (37) disintegrates into two equations:

$$
\begin{aligned}
& R_{a}=R_{c}+k_{f f}^{\prime} R_{f}=a X_{1}+k_{f f}{ }^{\prime} R_{f} ; \\
& X_{a}=X_{1}+k_{f f}^{\prime \prime} R_{f},
\end{aligned}
$$

where $a$ is as in (12). From (42) and (43) we have the sought-for quantities $X_{1}$ and $R_{f}$ : 


$$
\begin{aligned}
& X_{1}=\frac{k_{f f} " R_{a}-k_{f f} X_{a}}{a k_{f f} "-k_{f f}{ }^{\prime}} ; \\
& R_{f}=\frac{R_{a}-a X_{a}}{k_{f f}-a k_{f f} "} .
\end{aligned}
$$
(12):

The impedance to fault place should be determined using proportion $a$ from

$$
\dot{Z}=a X_{1}+j X_{1}=(a+j) X_{1} .
$$

The distance to the fault place is determined as usual (by (18)).

Thus we obtain the sought-for $l$ and $R_{f}$ values provided we know the fault quotient $\dot{k}_{f f}$. To obtain its value, loop current $\dot{I}_{I I}$ is to be found. For this purpose, we are forced to use equation set (34), which contains five unknowns: $\dot{Z}, R_{f}, \dot{I}_{I I}$, $\dot{e}_{C B}$, and $\dot{e}_{B A}$. The three-phase voltage system of remote end $\mathrm{J}$ is supposed to be symmetrical, hence $\dot{e}_{B A}=\dot{a} \dot{e}_{C B}$ (the phase factor $\dot{a}$ turns $\dot{e}_{C B}$ through $120^{\circ}$ ), and in the three equations of set (34) four unknowns, $\dot{Z}, R_{f}, \dot{I}_{I I}$ and $\dot{e}_{C B}$, remain. If we assume some value of $\dot{Z}$, then $\dot{I}_{I I}$ can be obtained from set (34) as

$$
\dot{I}_{I I}=\frac{\dot{E}_{B A}-\dot{Z}_{C}-2 \dot{Z}_{e} \dot{I}_{A}+\dot{a}\left[R_{f} \dot{I}_{C}-\left(\dot{Z}_{e}-Z\right) \dot{I}_{A}\right]}{\dot{a}\left[2\left(\dot{Z}_{e}-\dot{Z}\right)+R_{f}\right]+\left(\dot{Z}_{e}-\dot{Z}\right)} \text {. }
$$

Here we venture to assume still one unknown - the sought-for quantity $R_{f}$. This can be done because it is related by (42) to the known value $R_{a}$. In a phase-to-phase fault we have arrived at the fallacious circle once again: to determine the first quantity we should know the second one, but for finding the second quantity the first one is needed. The problem can be solved by repeating the iteration process.

To calculate the distance to fault place, we have the following input data: the faulty and remote line parameters $R_{c s p}, X_{1 s p}, \dot{Z}_{l i}, \dot{Z}_{r}$; and the measured fault quantities $\dot{E}_{B A}, \dot{E}_{C B}, \dot{I}_{B}, \dot{I}_{C}$.

The calculation procedure is the following: $a$ is calculated by (12); $\dot{Z}_{e}-$ by (35); and $\dot{Z}_{a}, R_{a}, X_{a}-$ by (40).

The first iteration cycle consists of the following steps:

1) assume the initial value of $\dot{I}_{\text {IIass }}{ }^{(0)}=0$;

2) calculate the first value of fault quotient $\dot{k}_{f f}^{(1)} ; k_{f f}{ }^{(1)} ; k_{f f}{ }^{\text {,(1) }}$ by (41), inserting the initial value of $\dot{I}_{I I}$;

3) calculate the reactance to fault place $X_{I}^{(1)}$ by (44);

4) calculate the distance to fault place $l^{(1)}$ by (18);

5) calculate the fault resistance $R_{f}^{(1)}$ by (45);

6) assume the first value of reactance to fault place based on the value calculated as above (step 3); $X_{\text {lass }}^{(1)}=X_{I}^{(1)}$ could also be assumed;

7) calculate the impedance to fault place $\dot{Z}^{(1)}$ by (46), inserting the assumed reactance to fault place $X_{\text {lass }}$;

8) calculate the first value of loop current $\dot{I}_{I I}^{(1)}$ by (47). 
The second iteration cycle starts with step 1). If the second value of the distance to fault place $l^{(2)}$ intolerably differs from the previous one $\left(l^{(1)}\right)$, continue the process.

In parallel lines, mutual inductance can be considered not existent, since the faulty line parameters do not change. The currents in all three phases of the parallel line are measured together with those of the faulty line. To determine current $\dot{I}_{I I}$ through fault resistance $R_{f}$, the superposition method can be applied. First, in accordance with the expounded above, we calculate the first values $X_{l}, R_{f}$ and current $\dot{I}_{I I}{ }^{\prime}$ observing no currents of the parallel line. Second, based on the calculated above values of $X_{1}$ and $R_{f}$, current $\dot{I}_{R f}$ is found as a result of currents in the parallel line. The sum $\dot{I}_{I I}$ of two currents $\dot{I}_{I I}{ }^{\prime}$ and $\dot{I}_{R f}$ and the other calculated values serve for the second cycle of iterative calculations.

\section{CONCLUSIONS}

1. The fault quotient enables convenient calculation of the currents from the opposite side of a line and of the capacitive currents by determining the distance to the fault place in power lines; for this purpose the apparent impedance method is applied.

2. This quotient proves its worth in high- and medium-voltage lines irrespective of the neutral grounding.

3. The role of the fault quotient increases with fault resistance. When this resistance is zero, the fault quotient does not influence calculation, since in this case apparent reactance $X_{a}$ and resistance $R_{a}$ are proportional: $R_{a}=a X_{a}$.

4. The fault quotient is determined as the ratio of the current through the fault place to that being the basic quantity in the calculation of apparent impedance.

5. The fault quotient is an indispensable quantity when parallel lines are concerned, although its determination is in this case more tedious.

6. For one-terminal lines at single-phase-earth faults, neglecting capacitive and load currents, the load quotient equals 1 , and at phase-to-phase faults it is $1 / 2$. In other cases it is a complex quantity (for single-phase-earth faults with the absolute value greater than 1).

\section{ACKNOWLEDGEMENT}

I express my gratitude to RTU Prof. J. Rozenkrons for relevant correction of the work.

\section{REFERENCES}

1. Survilo, J. (2008). Application of apparent impedance method at variable specific resistance of phase conductor. Latv. J. Phys. Tech. Sci., (1), 25-40.

2. Survilo, J. (2006). Once more on single-terminal algorithms for location of power line faults. Latv. J. Phys. Tech. Sci., (6), 15-23.

3. Фабрикант, В.Л. (1978). Дистанционная защита. Москва: Высшая школа, 214.

4. Survilo, J., \& Sauhats, A. (2005). The use of classical algorithm of phase-to-earth fault distance protection for determining the fault true impedances. Scientific proceedings of Riga Technical University; Power and electrical engineering, 14 (4), 146-157.

5. Fernando Calero. Schweitzer Engineering Laboratories, Inc. Mutual impedance in parallel lines: protective relaying and fault location considerations. www.selinc.com/techpprs/6283_MutualImpedance_FC_20070912.pdf 


\section{BOJĀJUMA KOEFICIENTA LOMA, NOTEICOT ATTĀLUMU LİDZ BOJĀJUMA VIETAI}

\section{J. Survilo}

\section{Kopsavilkums}

Bojājuma koeficienta jēdziens attiecas uz vienfāzes un divfāžu îsslēgumiem vienvirziena un divvirzienu, savrup- vai paralēlas elektropārvades līnijās pie attāluma noteikšanas līdz bojājuma vietai, pielietojot „redzamo pretestību” metodi. Bojājuma koeficientu noteic kā samēru starp strāvu bojājuma vietā un bojātās fāzes strāvu pie vienfāzes îsslēgumiem un starp strāvu bojājuma vietā un bojāto fāžu strāvu starpību pie divfāžu īsslēgumiem. Vienvirziena līnijās pie vienfãzes īsslēgumiem, neievērojot kapacitatīvās un slodzes strāvas, bojājuma koeficients ir vienāds ar 1, pie divfāžu īsslēgumiem tas ir 0,5. Citos gadījumos tas ir komplekss lielums un pie vienfāzes īsslēgumiem - ar absolūto vērtību, lielāku par 1. To nozīme ir jo lielāka, jo lielāka ir bojājuma pretestība $R_{f}$. Pie $R_{f}=0$, tam nav nekādas nozīmes, noteicot attālumu līdz bojājuma vietai. Bojājuma koeficienta leņķa ar reālo asi tangenss ieiet reaktīvās pretestības līdz bojājuma vietai un bojājuma pretestības noteikšanas izteiksmēs. Bojājuma koeficienta lietošana ir ērta attāluma līdz bojājuma vietai iteratīvos aprēķinos.

21.07.2008. 